\title{
$\mathrm{R}_{\text {oust }} \mathrm{EaD} \&$ \\ tecnologias digitais na educação
}

\section{Olhares de Norbert Elias: inclusão escolar do aluno surdo}

\author{
jakellinny Gonçalves de Souza Rizzo, UFGD \\ jake.librasufgd@gmail.com
}

\begin{abstract}
Resumo: $O$ presente trabalho objetiva relacionar as teorias de Norbert Elias estudadas durante as aulas da disciplina Educação, Diversidade e Identidade do Programa de Pós-Graduação em Educação (PPGEdu) - Mestrado da Universidade Federal da Grande Dourados (UFGD) com a vivencia dos alunos surdos em escolas comuns. Elias fala sobre a balança de poder, figuração interdependências entre as pessoas, que estão sempre em movimento, figurando as pessoas como estabelecidas em certos momentos, já em outro como outsiders. Os alunos surdos nas escolas comuns inúmeras vezes se encontram como outsiders por conta de sua língua, porém não permanecem nessa figuração se estiverem em uma escola direcionada para a educação de surdos como o INES.
\end{abstract}

Palavras-chave: Aluno surdo. Inclusão.

\section{Norbert Elias: suas teorias relacionadas com a vivência do aluno surdo em escola comum}

Este estudo é reflexo transcrito do conhecimento adquirido na disciplina Educação, Identidade e Diversidade do programa de Mestrado em Educação na Universidade Federal da Grande Dourados - UFGD, por meio da bibliografia apresentada e trabalhada na mesma.

O presente artigo tem como objetivo realizar uma relação sobre a inclusão escolar do aluno surdo com os conceitos presentes nos trabalhos de Norbert Elias. Com isso optou-se por uma pesquisa bibliográfica que será baseada nas obras "A civilização dos pais", "Sociedade dos indivíduos", "Escritos \& Ensaios 1- Estado, processo, opinião pública" "Os estabelecidos e os outsiders: sociologia das relações de poder a partir de uma pequena comunidade". Compreende-se com o estudo que processo civilizador ocorre por meio da interação entres os sujeitos, ou seja, é nas relações que nos construímos e nos construímos nas relações.

Para sistematizar a discussão serão abordados conceitos como Civilização, Figuração, Sociedade, Indivíduo, Relação de Poder "Estabelecidos e os Outsiders", Interde- 
pendência, fazendo uma ligação dos conceitos de Elias com a vivência do aluno surdo dentro da escola comum.

A civilização diz respeito a auto-regulação para controlar os afetos e pulsões, a civilização não é da natureza humana, é necessário que vivam com seus pares para alcançar essa civilização, trata-se de um processo universal. Pertence tanto as condições da individualização como da vida social, o processo de civilização só é possível pelo potencial de civilização biológico dos seres humano, para que consiga controlar seus impulsos e possa viver com os outros seres humanos, o processo civilizador é um processo de longa duração. As relações do processo civilizador podem ser em variados universos sociais, ou seja, modelos sociais, ambientes, "pessoas constituem teias de interdependência ou configurações de muitos tipos, tais como famílias, escolas, cidades, estratos sociais ou estados". Para Elias, o conceito de civilização expressa uma cadeia de lentas e longas transformações sociais de auto regulação, não de modo evolutivo e linear, mais sim de modo contínuo.

A partir da coação externa que se dá o desenvolvimento da autocoação e assim o autocontrole individual, ficando evidente que o processo civilizador contribui para mudanças nas atitudes sociais do individuo. Para Elias consequentemente essa regulação pode moldar o sujeito em seus impulsos e emoções estabelecendo melhores relações sociais entre os indivíduos em uma sociedade.

Os desafios que se colocam à inclusão escolar estão postos, pois atualmente tem sido de fato um grande o desafio para as escolas garantirem a inclusão do aluno surdo, já que os mesmo tem necessidades educativas especiais principalmente, nas questões de sua linguagem. A educação de surdos que, por muito tempo, foi negligenciada ou até mesmo excluídos por questões culturais, sociais, pois eram vistos como incapazes por conta de seu atraso na aquisição da linguagem, já que os surdos muitas vezes tem dificuldade no desenvolvimento educacional.

Desde o nascimento, quando uma criança surda nasce em família ouvinte, seu processo de socialização é conflituoso, pois os pais tem uma frustação para aceitar a criança "diferente". Uma das reflexões postas por Elias é a necessidade do reconhecimento dos direitos das crianças, de ser compreendida em suas características próprias, como uma questão de direitos, o mesmo deve acontecer com as pessoas surdas, devem ser respeitadas suas propriedades linguísticas, sua cultura e identidade surda.

As comunidades surdas tiveram seus direitos linguísticos prejudicados em 1880 no congresso de Milão, um evento que reuniu intelectuais que demostraram que as pessoas surdas não tinham problemas na emissão de voz nem no aparelho fonador, ou seja, podiam falar. A partir disso foi imposto que a língua de sinais fosse suspensa das práticas sociais e educacionais dos surdos, adotando a oralização, o principal objetivo dessa teoria era desenvolver a fala dos surdos, pois acreditava-se que língua oral era primordial para a comunicação.

Antigamente existiam muitos casos de abandono de crianças, elas eram jogadas em rios, nos estercos ou até mesmo em fossas, pois davam trabalho, choravam e gritavam muito, na época não existiam leis contra assassinatos. (ELIAS, 2012).

$\mathrm{O}$ mesmo acontecia com as pessoas surdas, que antigamente eram rejeitados pela sociedade e posteriormente eram isolados nos asilos para que pudessem ser protegidos, pois não acreditava que pudesse ter uma educação em função da sua anormalidade, ou seja, aquela conduta marcada pela intolerância obscura na visão negativa sobre os surdos vistos como "anormais" ou "doentes" (PERLIN; STROBEL, 2006, p.06). 
Os seres humanos formam balanças de poder uns com os outros, uma relação de interdependência recíproca que se estabelece entre os indivíduos e a sociedade. $O$ autor aponta que é necessária a apropriação de uma língua especificamente social, sem isso está fora de todas as configurações humanas, e até mesmo não é propriamente um ser humano, pois não seriam capazes de se orientar nem se comunicar com os outros. A inter-relação das pessoas acontece principalmente através da linguagem, essa interrelação que de alguma forma se entrecruzam e estabelecem uma interdependência entre os sujeitos são denominadas pelos autores de configurações, como uma teia de relações entre os indivíduos ligados entre si.

A ideia de interdependência para o autor é que "eu", "você", "ele", "ela", "nós" e "eles" nenhum desses existem sem o outro. O que para Elias seria a sociedade, pois não há sociedade sem individuo nem individuo sem sociedade, se constitui como uma estrutura organizacional, um conjunto de relações e um todo relacional, com diversas formas de entrelaçamentos sociais e inter-relacionamentos que de maneira alguma vai acontecer individualmente, os indivíduos fazem a sociedade e a sociedade faz o individuo.

Essa relação entre a sociedade e o individuo pode ser exemplificada pelas pessoas com algum tipo de deficiência, sendo que cada um tem suas particularidades estando mais ou menos dependentes, no caso do aluno surdo que depende de uma interprete de libras em todo seu processo educacional.

$\mathrm{Na}$ escola não havendo um professor proficiente em LIBRAS em sala de aula, o profissional Tradutor intérprete de LIBRAS (TILS) é fundamental para a comunicação. Esse profissional surgiu com a necessidade da comunidade surda de possuir um mediador no processo de comunicação com os ouvintes. Sabe-se que informalmente membros da família faziam essa função, por não conhecerem a Língua de Sinais, construíam uma comunicação usual própria, diferente da Língua de Sinais, com assuntos relacionados apenas as necessidades básicas e momentâneas da criança Surda (CASTRO, 1999).

Com essa necessidade de apropriação de língua os surdos tiveram muitas dificuldades, eram excluídos por se comunicar pela linguagem de sinais, como apresentado acima em determinados momentos foram até proibidos de sinalizarem, inclusive em contextos educacionais. Somente em 24 de abril de 2002 foi aprovada no Brasil a Lei no 10.436 visando atender as especificidades linguísticas das pessoas surdas, garantindo uma condição mais digna para a comunidade surda, reconhecendo a Língua Brasileira de Sinais - libras com segunda língua oficial da Brasil.

Os seres humanos singulares transformam suas figurações, em determinada situações um individuo tem "autonomia e poder" quanto ao outro, porém em outro momento esse poder é invertido, quem antes não tinha "autonomia e poder" passa a ter, e o que tinha já não tem mais, as mesmas pessoas podem formar diferentes figurações umas com as outras, quem muda não são as pessoas mais sim as relações de poder.

Essa relação de poder pode ser compreendida entre os "estabelecidos e os outsiders", são as relações de poder o que diferem, um grupo tem poder, econômico, social ou até mesmo os linguísticos, ocupam posições de influencia e prestigio, se percebem como os melhores, com isso excluem os outsiders que são os piores, que não tem acesso a recursos de poder. Contudo aqueles que são socialmente e linguisticamente configurados como outsiders podem ser estabelecidos em outros momentos, pois para Elias ninguém é mais sim, está!

A escola com a perspectiva de educação inclusiva parte do princípio de que a escola comum é o lugar para todos, em razão disso é constituída por vários grupos, quan- 
do se trata dos alunos surdos e ouvinte a uma divisão de poder intergrupal por conta da linguagem.

A comunidade escolar esta entrelaçada muitas vezes com os estabelecidos que são ouvintes e os outsiders que são os surdos, isso remete que até mesmo nas relações de poder as pessoas estão inter-relacionadas, isso poderia explicar o problema da exclusão com um dos grupos, considerando a figuração dos grupos e sua interdependência.

Pode-se configura-los dessa forma visto que existe diferenças entre os alunos surdos e ouvintes nas relações de poder dentro da escola, os surdos chegam a um ambiente social onde na maior parte dos casos os professores e os dos alunos são ouvintes "estabelecidos" e de alguma forma acabam excluindo e não aceitam em sua totalidade os surdos "outsiders", onde são o grupo minoritário dentro da escola.

Essa balança de poder dos ouvintes sobre os alunos surdos os tornam excluídos diariamente dentro da escola, é indiscutível que essa não aceitação é consequência da linguagem, onde são deixados em um isolamento social e linguístico.

Todavia como a balança está sempre em movimento essa situação se inverteria se estivéssemos falando do Instituto Nacional de Educação de Surdos - INES que atende em torno de 600 alunos surdos, da Educação Infantil até o Ensino Médio, aqui os surdos são os "estabelecidos" e os ouvintes se configura como "outsiders".

No espaço escolar encontra-se muito preconceito linguístico entres os profissionais e alunos, além do mais os professores por não conhecer a libras não estabelecem um diálogo com o aluno, porém esses professores pertencem à teia de interdependência, por meio de suas ações, práticas pedagógicas, metodologia, ou seja, as condições que oferecem a esses alunos são determinantes para que todos os indivíduos do seu grupo social consiga romper com essas diferenças no contexto escolar.

De acordo com Gonçalves e Festa (2013, p. 02) a inclusão escolar deve ocorrer, ainda que existam desafios, com garantia de oportunidades ao aluno Surdos iguais aos do aluno ouvinte. A presença do aluno Surdo em sala exige que o professor reconheça a necessidade da elaboração de novas estratégias e métodos de ensino que sejam adequados à forma de aprendizagem deste aluno Surdo, o aluno Surdo está na escola, então cabe aos professores criar condições para que este espaço promova transformações e avanços a fim de dar continuidade a um dos objetivos da escola, ser um espaço que promove a inclusão escolar.

\section{Considerações Finais}

Considerando o estudo realizado percebe-se que as relações de poder advém da figuração do individuo na sociedade, na escola constituem teias de interdependência ou configurações por um grupo mutável estruturado por professores, alunos, diretores etc. cabendo a esses a responsabilidade de promover mudanças nas relações sociais quais são necessárias para superar essas dificuldades linguísticas entre os surdos e ouvintes, oferendo uma educação inclusiva e com isso aceitar as diferenças como diversidade cultural e linguística.

A Libras não é exclusivamente para pessoas surdas, todos os ouvintes da escola deveriam se apropriar dessa língua para interagir como os alunos surdos, nas aulas, no intervalo, dessa maneira todos trabalhar para fortalecer essa ação e tornar uma a escola inclusiva, rompendo essa balança de poder entre os "estabelecidos" e "outsiders" onde 
todos possam garantir seus direitos educacionais, transformando a escola em um espaço de harmonia e não mais disputa de poder.

\section{Referências}

CASTRO, R. G. Libras: uma ponte para comunicação entre pais ouvintes e filhos surdos. Trabalho de Conclusão de Curso (Especialização em Educação Especial Infantil e Fundamental). Maringá: Universidade Estadual de Maringá, 1999.

ELIAS, Norbert. A sociedade dos indivíduos. Rio de Janeiro: Zahar, 1994.

.civilização dos pais. Revista Sociedade e Estado. Vol. 27, Número 3, p. 469-493, setembro/dezembro Rio de Janeiro, 2012.

.Escritos \& Ensaios: 1 estado, processo, opinião pública v. 1, Rio de Janeiro: Jorge Zahar Ed., 2006.

ELIAS, N.; SCOTSON, J. Os estabelecidos e os outsiders: sociologia das relações de poder a partir de uma pequena comunidade. Tradução: Vera Ribeiro. Rio de Janeiro: Jorge Zahar, 2000.

FRIAS, E. M. A. Inclusão escolar do aluno com necessidades educativas especiais: contribuições ao professor do Ensino Regular. Disponível em: <http://www.diaadiaeducacao.pr.gov.br/portals/pde/arquivos/1462-8.pdf>. Acesso em: 24/07/2016.

Instituto Nacional de Educação de Surdos. Conheça o INES. Disponível em: <http://www.ines.gov.br/conheca-o-ines>. Acesso em: 23/07/2016

PERLIN, Gladis; STROBEL, Karen. Surdos: vestígios culturais não registrados na história. Dissertação de mestrado em fase de elaboração, na área de educação GES/UFSC, 2006.

Gonçalves, Humberto Bueno, Festa, Priscila Soares Vidal. Metodologia do professor no ensino de alunos surdos. Revista Eletrônica do Curso de Pedagogia das Faculdades OPET. Dezembro, 2013. Disponível em: < http://www.opet.com.br/faculdade/revistapedagogia/pdf/n6/ARTIGO-PRISCILA.pdf>. Acesso em 23/07/206. 